\title{
Failure mode analysis on compression of lattice structures with internal cooling channels produced by laser powder bed fusion
}

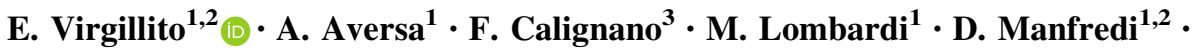 \\ D. Ugues ${ }^{1} \cdot$ P. Fino ${ }^{1}$
}

Received: 24 September 2020/Revised: 7 December 2020/ Accepted: 28 January 2021/Published online: 11 March 2021

(C) The Author(s) 2021, corrected publication 2021

\begin{abstract}
Conformal cooling coils have been developed during the last decades through the use of additive manufacturing (AM) technologies. The main goal of this study was to analyze how the presence of an internal channel that could act as a conformal cooling coil could affect compressive strength and quasi-elastic gradient of AlSi10Mg lattice structures produced by laser powder bed fusion (LPBF). Three different configurations of samples were tested in compression at $25{ }^{\circ} \mathrm{C}$ and $200{ }^{\circ} \mathrm{C}$. The reference structures were body centered cubic (BBC) in the core of the samples with vertical struts along $Z$ (BCCZ) lattices in the outer perimeter, labelled as NC samples. The main novelty consisted in inserting a straight elliptical channel and a $45^{\circ}$ elliptical channel inside the BCCZ lattice structures, labelled as $\mathrm{SC}$ and $45 \mathrm{C}$ samples respectively. All the samples were then tested in as-built (AB) condition, and after two post process heat treatments, commonly used for AlSi10Mg LPBF industrial components, a stress relieving (SR) and a T6 treatment. NC lattice structures $\mathrm{AB}$ exhibited an overall fragile fracture and therefore the SC and $45 \mathrm{C}$ configuration samples were tested only after thermal treatments. The test at $25{ }^{\circ} \mathrm{C}$ showed that all types
\end{abstract}

Supplementary Information The online version contains supplementary material available at https://doi.org/10.1007/s40436021-00348-z.

E. Virgillito

enrico.virgillito@polito.it

1 Department of Applied Science and Technology, Polytechnic University of Turin, 10129 Turin, Italy

2 Center for Sustainable Future Technologies IIT, Italian Institute of Technology, 10144 Turin, Italy

3 Department of Applied Science and Technology, Polytechnic University of Turin, 10129 Turin, Italy of samples were characterized by negligible variations in their quasi-elastic gradients and yield strength. On the contrary, the general trend of stress-strain curves was influenced by the presence of the channel and its position. The test at $200{ }^{\circ} \mathrm{C}$ showed that $\mathrm{NC}, \mathrm{SC}$ and $45 \mathrm{C}$ samples after SR and T6 treatments exhibited a metal-foam like deformation.

Keywords Laser powder bed fusion (LPBF) - Conformal cooling channel - Lattice structures - Failure mode analysis $\cdot$ Mechanical properties at $200{ }^{\circ} \mathrm{C}$

\section{Introduction}

Additive manufacturing (AM) has revolutionized many industrial sectors including the mold industry. In fact, in the last few years some studies showed the possibility of creating molds with conformal cooling coils, i.e., channels that optimized thermal distribution and sped up cooling and production times, through additive technologies [1, 2]. In addition, thanks to AM processes, lattice structures were easily included into the mold bulk in order to minimize the mass of the component maintaining constant structural characteristics and enhancing heat dissipation [3]. Generally, research activities on AM molds are focused on the mold design, that is optimized through numerical simulation to improve heat exchange $[4,5]$ or to evaluate the structural characteristics of lattice samples $[6,7]$.

Besides the mold industry, the use of lattice structures in light alloys produced by AM has also been adopted in other industrial sectors, such as automotive or aerospace due to the lightweight and the obvious related benefits, encouraging the development and characterization of different types of lattices, such as faces centered cubic (FCC), body 
centered cubic (BCC), their variants with reinforcement rods along the $Z$ axis (FCCZ or BCCZ), gyroid and diamond lattices $[8,9]$. In particular, in the last years an increasing number of papers presented the mechanical responses of various types of AM trabecular structures, from static [10-15] to dynamic [16-18] points of view. Most of these studies $[8,10,11,15]$ were focused on the evaluation of load-bearing capacity of the different lattice types. Other investigations evaluated the effects of the number and dimension of cells and of the struts [10, 12] and of the volume fraction $[13,14]$ on the mechanical performances of lattice structures. Furthermore, other studies confirmed that the fracture process depended on lattice type and number of layers [8, 19], volume fraction and lattice parameters [20-23] and thermal treatment applied [24, 25]. The type of fracture is a key aspect to assess in the tested samples $[10,11,14]$ due to the fact that stable fracture modes prevent catastrophic component failure.

Through the choice of design parameters for the construction of the lattice structures [21] and the correct evaluation of their volume fraction [20,22], it is possible to modulate their static mechanical characteristics. By varying the relative density of the samples, results similar to the model proposed by Gibson-Ashby for foams were obtained for aluminum lattice structures [20, 22].

In addition, a recent study focused on AlSi10Mg BCCZ structures by laser powder bed fusion (LPBF)—-the ISO/ ASTM 52900 standard name of the process also known in literature as selective laser melting (SLM) or direct metal laser sintering (DMLS) - revealed that the number of layers and cells affected Young's modulus, compressive strength and fracture mode [19]. It was demonstrated that as the number of layers increased both the initial compressive strength and the quasi-elastic gradient decreased. In addition, whereas in BCCZ mono-layer samples' fracture was caused by $Z$ axis strut buckling and subsequent collapse of the diagonal struts, in samples with more than 5 layers the load-bearing capacities of cells decreased by the unconstrained boundary conditions of nodes. In another study, Ferro et al. [23] observed that in BCCZ samples with more than 5 layers the damaging process was based on the shear band fracture with localized fracture zones and no evidence of a homogeneous plastic deformation through the samples.

On the other hand, the fracture conditions of AlSi10Mg lattice structures can be modified also through suitable post process heat treatments $[24,25]$. It is well known that AM products are often treated with annealing to reduce residual stresses due to repeated heating and cooling and high thermal gradients $[26,27]$. In other studies, solutioning, quenching and artificial aging heat treatments (T6) were carried out on LPBF aluminum parts to study the effects on mechanical properties, despite the loss of the very fine microstructure, typical of the as-built (AB) state. It has been demonstrated that $\mathrm{AB}$ parts have superior mechanical strength compared to thermally treated ones, with a lower ductility [27, 28]. As known, this behavior can be explained considering the strengthening given by the interactions of dislocations and residual stresses [29].

However, putting together the extensive research which has been carried out on trabecular structures produced by AM for the mold industry and for lightweight structural applications, to the authors knowledge there is not a study to evaluate the effects of introducing in the lattice design a channel for a conformal cooling coil on the lattice structure mechanical behavior. Therefore, the main goal of this study was to analyze how the presence of internal channels could affect compressive strength and quasi-elastic gradient of AlSi10Mg lattice structures produced by LPBF. Starting from the work carried out by Ferro et al. [23], the fracture behavior was assessed for lattice samples with and without a cooling coil inside the structure at room temperature and at $200{ }^{\circ} \mathrm{C}$. This temperature is considered of great interest in designing lightweight structures in aluminum alloy by LPBF able to work also as heat-exchanging systems. The samples with channels were produced in two different configurations in order to evaluate the effect of the relative internal position and in order to have two simple "bricks" which can be used as starting elements to design more complex structures. Samples were tested in AB condition and after two post process thermal treatments, a stress relieving (SR) and a T6.

\section{Materials and methods}

AlSi10Mg spherical powder used in this work was produced by gas atomization (EOS $\mathrm{GmbH}$ ), with a mean size of $24 \mu \mathrm{m}$. The chemical composition is reported in Table 1, as specified in the supplier datasheet [30].

On the basis of a previous study [23], the lattice structures considered have BCC type cell in the sample core and $\mathrm{BCC}$ with struts along $Z$ axis (BCCZ) in the perimetric

Table 1 AlSi10Mg powder chemical composition (mass fraction, \%)

\begin{tabular}{lllllllllll}
\hline $\mathrm{Al}$ & $\mathrm{Si}$ & $\mathrm{Fe}$ & $\mathrm{Cu}$ & $\mathrm{Mn}$ & $\mathrm{Mg}$ & $\mathrm{Ni}$ & $\mathrm{Zn}$ & $\mathrm{Pb}$ & $\mathrm{Sn}$ & $\mathrm{Ti}$ \\
\hline Balance & $9.0-11.0$ & 0.55 & 0.05 & 0.45 & $0.2-0.04$ & 0.05 & 0.10 & 0.05 & 0.05 & 0.15 \\
\hline
\end{tabular}


outer cells of the specimens. The whole outer dimensions for the samples are $21.0 \mathrm{~mm}$ length, $21.0 \mathrm{~mm}$ width and $41.4 \mathrm{~mm}$ height. The relative density, i.e., the ratio of the density of the actual structure to that of the bulk specimen, was set uniform for all specimens and equal to 0.4. On the basis of results described by Ferro et al. [23] in order to maximize sample quasi-elastic gradient and yield strength, BCCZ structures with cells size of $4 \mathrm{~mm}$ and struts diameter of $1.2 \mathrm{~mm}$ were exploited. The studied structure consists of 10 planes of elementary cells reinforced by 2 continuous outer surfaces at the basement and at the top of the specimen. Three configurations of specimens were designed and labelled as follows (see Fig. 1).

(i) NC: with no channel, studied as a reference;

(ii) SC: with straight channel, in which the channel is placed parallel to one of the smaller sides of the specimens;

(iii) 45C: with $45^{\circ}$ channel, in which the channel is placed at $45^{\circ}$ respect to one of the smaller sides of the specimens.

The SC and 45C samples could be considered as starting elements to build a more complex lightweight structure with a lattice network and a cooling coil inside it.

The design of the elliptical channel in SC and 45C specimens was optimized from a mechanical and hydraulic point of view. Firstly, it could be manufactured by LPBF without support structures inside being self-sustaining; secondly, good mechanical responses could be obtained for compressive stresses along the major axis of the ellipse and then the external pressure drop could be minimized [31].

The AlSi10Mg lattice specimens were produced using an EOSINT M270 machine Dual Mode (EOS GmbH). The machine is equipped with a $\mathrm{Yb}$ fiber laser system of $200 \mathrm{~W}$ and a nominal spot diameter of $100 \mu \mathrm{m}$. In this work, the building platform was kept at $100{ }^{\circ} \mathrm{C}$, and the main process parameters employed were a laser power of $195 \mathrm{~W}$, a scanning speed of $800 \mathrm{~mm} / \mathrm{s}$ and a hatch distance of 0.17 $\mathrm{mm}$, to ensure high density of the struts, as demonstrated in previous studies [23, 32]. The specimens were built with supports at the square base to avoid distortions during growth. After the LPBF process, all specimens were detached by manual operations and polished to guarantee planar and parallel surfaces.

With respect to the specimen nominal dimensions, the produced ones are characterized by slightly different values, as appreciable from average (Mean) and standard deviation (Std. Dev.) data reported in Table 2. However, as confirmed by mass measurements, the relative density of each sample configuration is equal to the nominal 0.4.

Mechanical tests were carried out to define the static behavior of three specimens for each configuration. The obtained results of tests were processed to determine the
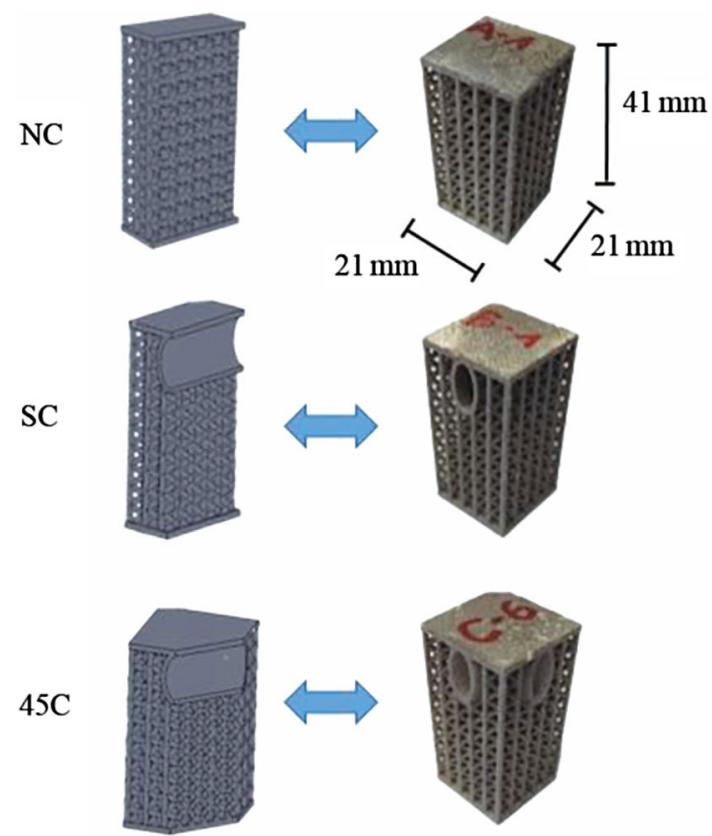

Fig. 1 Comparison between CAD project for the three configuration considered and AlSi10Mg samples produced by LPBF, from top to bottom: NC, SC and 45C samples

mean curves representative of the mechanical behavior. In order to compare the effect of post process heat treatments, specimens were analyzed $\mathrm{AB}$, after an SR treatment consisting of $2 \mathrm{~h}$ at $300{ }^{\circ} \mathrm{C}$ [32], and after a T6 treatment. The T6 consisted of a solution treatment of $5 \mathrm{~h}$ at $530{ }^{\circ} \mathrm{C}$, followed by water quenching, and then an artificial aging for $12 \mathrm{~h}$ at $160{ }^{\circ} \mathrm{C}$ [33].

The specimens were subjected to uniaxial compression tests according to ISO 13314: 2011 in Ref. [36] and considered as metallic foams. The tests were performed using a Zwick-Roell electro-mechanical testing machine with a $100 \mathrm{kN}$ load cell. The trabecular nature of the samples did not allow to use conventional methods for deformation acquisition (strain-gages or extensometers), so the deformations were acquired through the displacement of the crosspiece and the test was carried out in position control. To avoid slipping effects of the specimen during data

Table 2 Average geometrical feature values with their standard deviation values measured for lattice structures analyzed

\begin{tabular}{llllll}
\hline Specimen & Length/mm & Width/mm & Height/mm & Weight/g \\
\hline NC & Mean & 21.22 & 21.23 & 41.34 & 19.87 \\
& Std. Dev. & 0.05 & 0.04 & 0.04 & 0.51 \\
SC & Mean & 21.19 & 21.21 & 41.30 & 20.09 \\
& Std. Dev. & 0.05 & 0.05 & 0.05 & 0.47 \\
45C & Mean & 21.15 & 21.17 & 41.29 & 19.92 \\
& Std. Dev. & 0.01 & 0.04 & 0.04 & 0.39 \\
\hline
\end{tabular}


acquisition, a $1 \mathrm{kN}$ preload was applied. The tests were carried out at $1 \mathrm{~mm} / \mathrm{min}$. The tests were carried out both at room temperature $\left(25{ }^{\circ} \mathrm{C}\right)$ and $200{ }^{\circ} \mathrm{C}$. To perform high temperature tests, the machine was equipped with a thermal chamber that allowed to evaluate the mechanical behavior in a range of temperatures up to $250{ }^{\circ} \mathrm{C}$. The following data were obtained.

(i) Quasi-elastic gradient, i.e., the slope of the curve in the elastic phase;

(ii) Yield strength, or the stress at which a specific amount of plastic deformation was produced, usually taken as $0.2 \%$ of the unstressed length.

In order to better understand the fracture mechanism of the NC samples, thermography was chosen as visual analysis in $\mathrm{AB}$ condition. By monitoring heat and its dissipation during the test, information on the fracture mode could be evaluated. An Optris camera model PI 400 was used to acquire thermal images. To improve their emissivity, tested samples were black-painted. The fracture surfaces were then observed with an optical stereo microscope (OM) Leica EZ4W. This type of analysis is not useful on thermal treated samples due to the collapsing of the lattice structure at the end of the compression tests. To evaluate the fracture mode of $A B$ samples, vision research high speed camera model Miro C110 was used to acquire data.

\section{Results and discussion}

In order to assess the performance of $\mathrm{AlSi} 10 \mathrm{Mg} \mathrm{BCCZ}$ lattice samples as reference, $\mathrm{NC}$ samples were tested at 25 ${ }^{\circ} \mathrm{C}$. Quasi-elastic gradient and yield strength of tested samples are summarized in Table 3. A quasi-elastic gradient very close to the $\mathrm{AB}$ condition was maintained with both the post process thermal treatments, considering a standard deviation less than $10 \%$, assuring a similar structural behavior. In Refs. [27, 28, 33, 35], it has been demonstrated that AB parts produced by SLM have superior mechanical strengths compared to thermally treated ones, but with more limited ductility.

Table 3 Static compressive properties of AlSi10Mg NC samples AB, SR, T6 tested at $25^{\circ} \mathrm{C}$

\begin{tabular}{lll}
\hline $\begin{array}{l}\text { Thermal } \\
\text { treatment }\end{array}$ & $\begin{array}{l}\text { Quasi-elastic gradient / } \\
\text { GPa }\end{array}$ & $\begin{array}{l}\text { Yield strength / } \\
\text { MPa }\end{array}$ \\
\hline AB & $2.2 \pm 0.2$ & $39.8 \pm 3.6$ \\
SR & $2.2 \pm 0.1$ & $29.8 \pm 2.1$ \\
T6 & $2.1 \pm 0.1$ & $30.1 \pm 1.6$ \\
\hline
\end{tabular}

In the case of $\mathrm{NC}$ specimens $\mathrm{AB}$, a rupture at the end of the elastic phase was observed. Therefore their fracture surfaces were analyzed identifying areas in which a brittle fracture occurred and areas in which struts underwent plastic deformations. In particular, some of the struts of the outer sample's border presented only evident signs of plastic work, with slipping bands on the whole surface, as shown in Fig. 2.

Indeed, in these zones of the samples, struts were characterized by ductile fracture surfaces, as already reported in Ref. [14]. On the contrary, all the fracture surfaces of struts inside the sample presented a uniform breakage of a fragile type. Moreover, the orientation of the border struts after the sample break allowed to understand that they underwent a flexural load since they faced towards the inside of the specimen. Furthermore, the areas subjected to plastic work were identified by thermography. It is possible to note that, at the end of a compression test, the average temperature of the specimen volume inside the white rectangle in Fig. $3 \mathrm{a}$ is $26.2^{\circ} \mathrm{C}$. Despite this, there are some external areas where the local temperature is much higher, with zones in which temperature rises up to $33.7^{\circ} \mathrm{C}$ (see Fig. 3b-d).

This localized temperature increase can be due to the plastic work carried out by the strut during the breaking phase. Indeed, due to micro-plasticity activation and dislocations motion, the intrinsic material dissipation may be expressed by a corresponding thermal emission. Therefore, in the fracture zones of the internal struts no heat development was measured and no plastic work was observed [37]. On the basis of the overall fragile fracture, as shown in the video of supplementary info called Online Resource 1 , AB lattice structures were then considered not technologically useful, and therefore the SC and $45 \mathrm{C}$ configuration samples were tested only after thermal treatments. In fact, it is well known that SR and T6 AlSi10Mg samples by LPBF exhibit ductile behavior, even if a lower yield

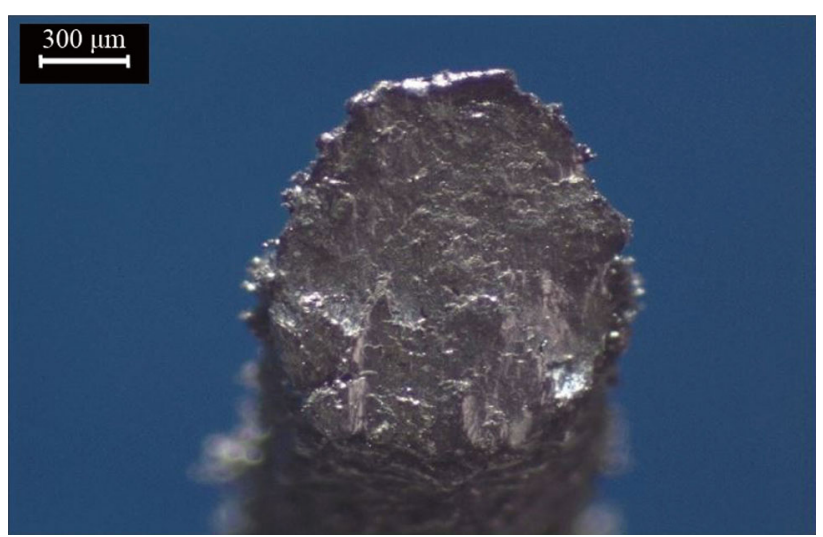

Fig. 2 Slipping bands on the fracture surface of external struts of AlSi10Mg NC sample $\mathrm{AB}$ tested at $25^{\circ} \mathrm{C}$ 


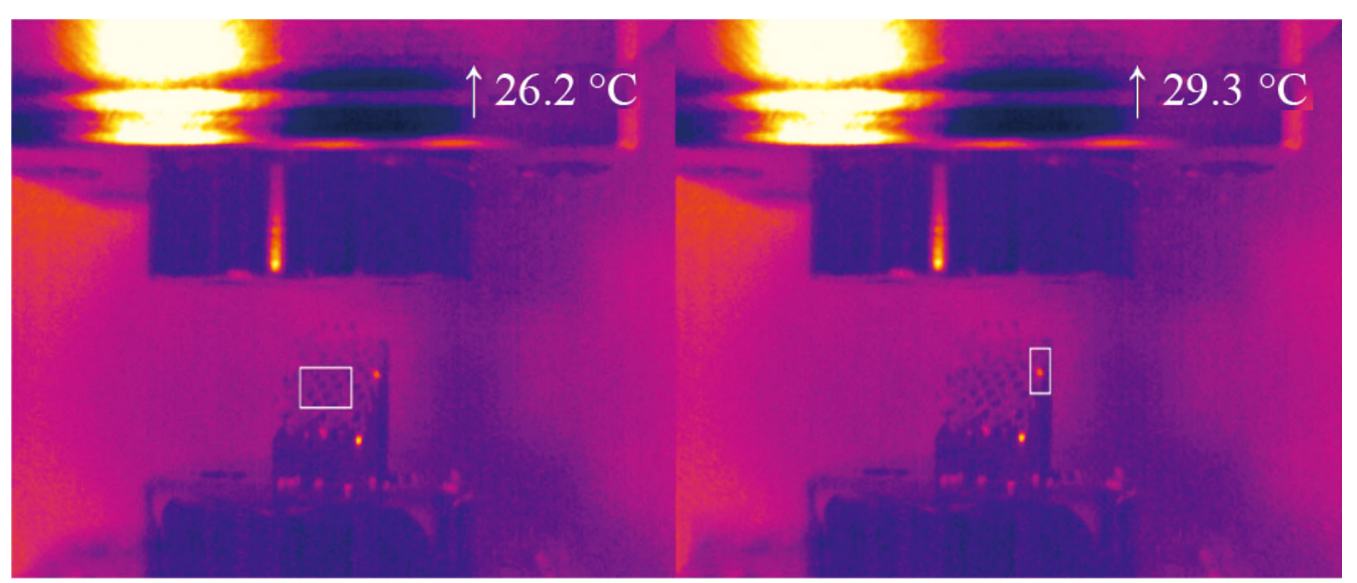

(a)

(b)

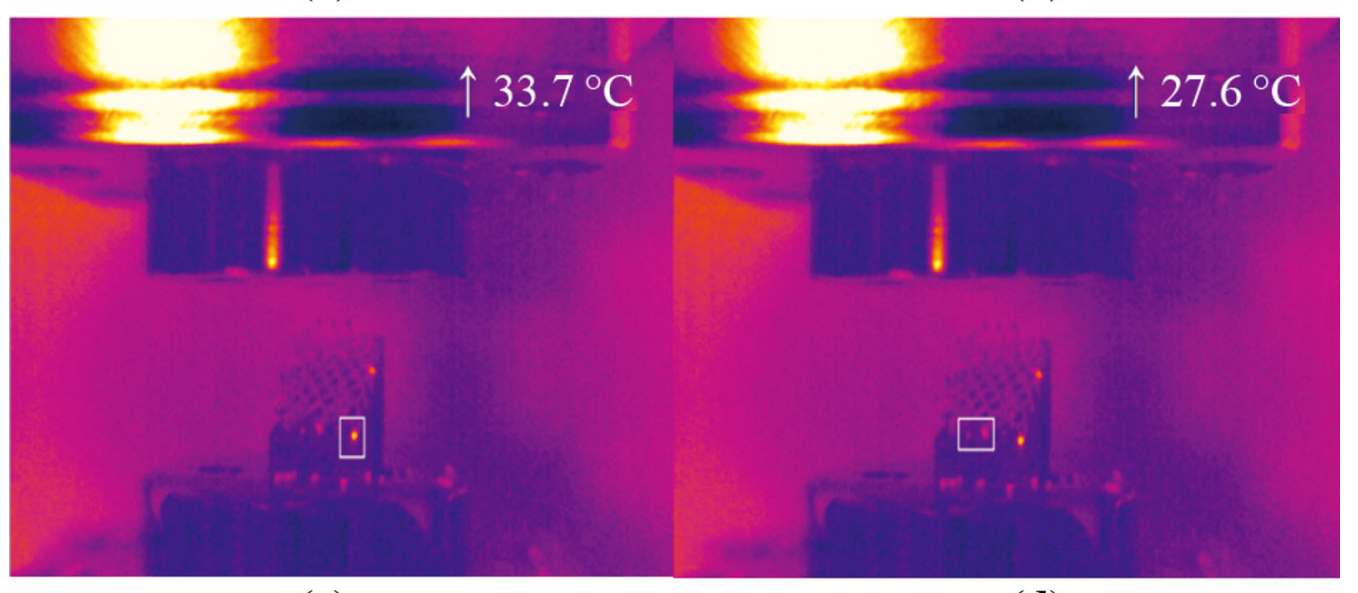

(c)

(d)

Fig. 3 Thermal images of the in-situ fracture of NC specimen in AB condition a internal zone, $\mathbf{b}$, $\mathbf{c}$ and $\mathbf{d}$ external zones

strength and a higher elongation at break are obtained after SR, with a similar microstructure at optical microscope with respect to the $A B$ condition [33-35]. While after T6, the yield strength increases and ductility reduces to values near $\mathrm{AB}$ condition, but with a coarser microstructure $[33,35]$.

Considering NC samples after SR and T6, the stressstrain graphs of Fig. 4 present the following trend: at the beginning of the plastic phase, there is a peak of tension $\left(\sigma_{\max }\right)$ followed by a quick stress decrease $\left(\sigma_{\min }\right)$, determining a drop of stresses $(\Delta \sigma)$. Moreover, the curves of Fig. 4 are characterized by a different evolution of falling stress corresponding to the sliding of the structure, observed in these samples along struts at $45^{\circ}$ with respect to $Z$-axis (as illustrated in Supplementary Fig. 4 for a NC sample after SR, as an example). It is known from literature that shear stresses in a material have their maximum value on planes at $45^{\circ}$ to the tensile axis [38]. The deformation began along the slipping planes more favorable and less energetic, probably due to the presence of defects or microporosity. Then deformation propagated along a direction perpendicular to these planes, allowing the structure to collapse, as already observed in Ref. [21].

As shown in Fig. 4, the SR samples have higher $\sigma_{\max }$ than the T6 ones. The improved mechanical strength of SR samples, however, is compensated by an earlier slipping behavior of structure. In fact, SR specimens slipped at $12.7 \%$ of strain $\left(\varepsilon_{\mathrm{min}, \mathrm{SR}}\right)$ while T6 ones at $16.5 \%\left(\varepsilon_{\mathrm{min}, \mathrm{T} 6}\right)$ with a greater $\Delta \sigma$ for the SR structures with respect to the T6 ones, with values of $-48 \%$ and $-28 \%$, respectively.

Once assessed the influence of the thermal treatments on the NC structures mechanical behavior, the focus moved on the effect of the channel presence in the lattice structure during compressive test at room temperature.

All types of samples were characterized by negligible variations in their quasi-elastic gradients and yield strength, as can be observed from the data summarized in Table 4, ensuring similar structural responses by configurations with or without channel.

On the other hand, the general trend of stress-strain curves is influenced by the presence and the type of channel, as can be seen in Fig. 5. It compares the stress- 


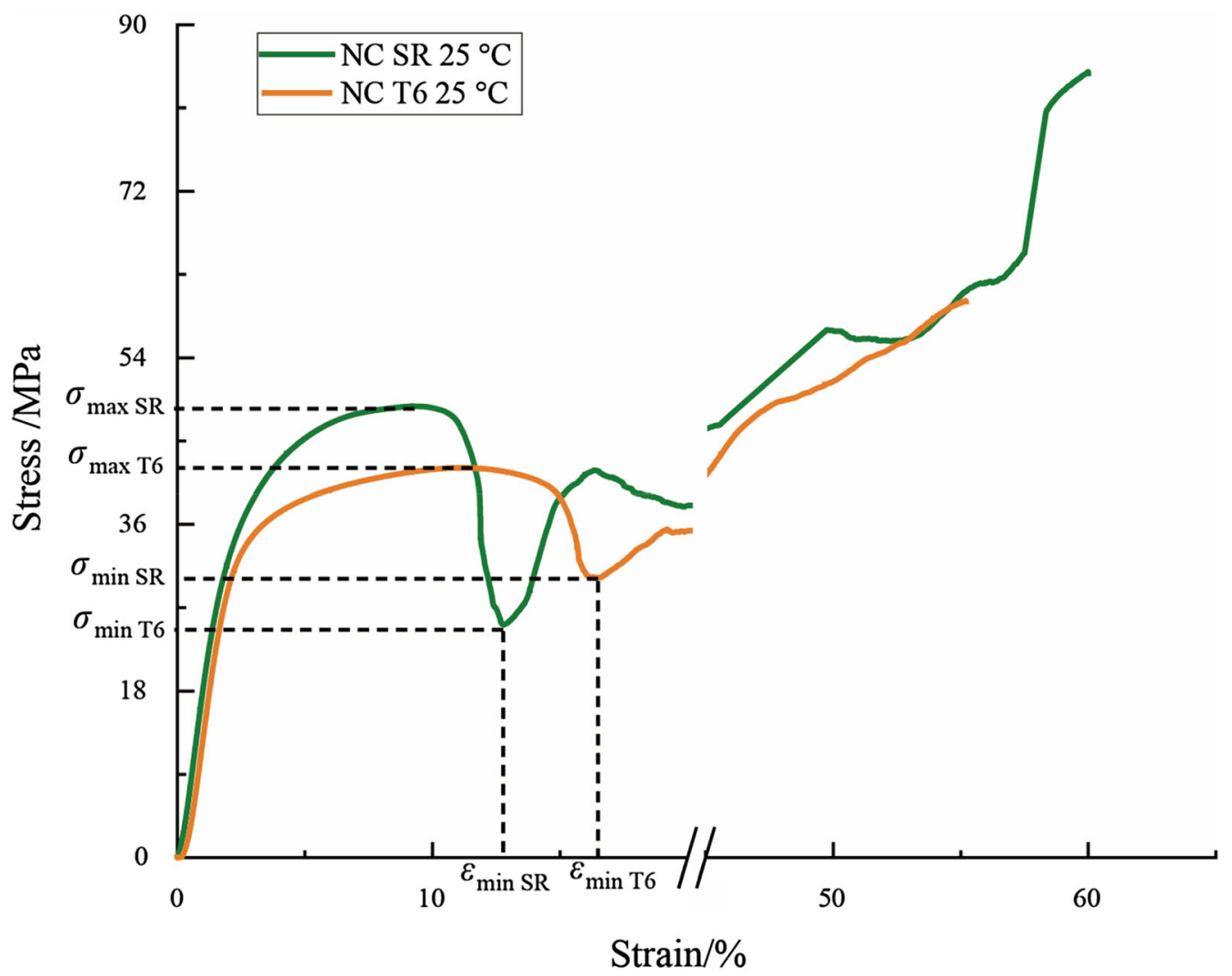

Fig. 4 Compressive stress-strain behavior obtained as mean curve for NC samples after SR and T6 tested at $25{ }^{\circ} \mathrm{C}$

Table 4 Compressive properties of SC and 45C samples after SR and $\mathrm{T} 6$ tested at $25^{\circ} \mathrm{C}$ in comparison with $\mathrm{NC}$ ones

\begin{tabular}{llllll}
\hline & \multicolumn{2}{l}{ Quasi-elastic gradient $/ \mathrm{GPa}$} & & \multicolumn{2}{l}{ Yield strength $/ \mathrm{MPa}$} \\
\cline { 2 - 3 } \cline { 6 - 7 } & SR & T6 & & SR & T6 \\
\hline NC & $2.1 \pm 0.1$ & $2.1 \pm 0.1$ & & $29.8 \pm 2.1$ & $30.1 \pm 1.6$ \\
SC & $2.1 \pm 0.2$ & $2.0 \pm 0.1$ & & $29.8 \pm 2.1$ & $25.6 \pm 2.9$ \\
45C & $2.0 \pm 0.2$ & $1.9 \pm 0.1$ & & $30.1 \pm 1.8$ & $27.5 \pm 2.3$ \\
\hline
\end{tabular}

strain mean curves recorded at $25{ }^{\circ} \mathrm{C}$ for the $\mathrm{NC}, \mathrm{SC}$ and $45 \mathrm{C}$ samples all after SR. The same trends were observed for the whole samples after T6.

As can be seen in the insets of Fig. 5, the NC samples presented higher $\sigma_{\max }$ and $\sigma_{\min }$ than the $\mathrm{SC}$ and $45 \mathrm{C}$ samples; moreover, the $\Delta \sigma$ is recorded at a greater percentage of deformation being $\varepsilon_{\min , \mathrm{NC}}>\varepsilon_{\min , 45 \mathrm{C}}>\varepsilon_{\min , \mathrm{SC}}$. There are also important differences between SC and 45C specimens: in fact, the latter have higher $\sigma_{\max }$ and $\sigma_{\min }$ than the former. The percentage deformation at which these events occur, $\varepsilon$ at $\sigma_{\max }$ and $\varepsilon$ at $\sigma_{\min }$, are also greater for the $45 \mathrm{C}$ samples than for the $\mathrm{SC}$ ones. It can be assumed that there is an influence in the elasto-plastic characteristics of the artifacts due to the presence and type of channels.
The slight higher mean value of strength of the $45 \mathrm{C}$ samples compared to the SC samples can be attributed to the number of elementary cells of the lattice. In SC and 45C structures a channel with an oval section with a major axis of $8 \mathrm{~mm}$ is present. In particular, in SC samples the channel is long as one side of the samples, whereas in $45 \mathrm{C}$ samples the channel length is equal to half the length of the diagonal of the specimen itself which, being a square base, will be equal to $\sqrt{2}$ length. Considering that the elementary cells measure $4 \mathrm{~mm}$ and that the side of the sample is approximately $20 \mathrm{~mm}$, 5 elementary cells for SC and 3.5 for $45 \mathrm{C}$ are eliminated considering as reference the section of the channel mid plane. In this way, considering the length of the major axis, the channel substituted a total of 10 cells for $\mathrm{SC}$ and 7 cells for $45 \mathrm{C}$, as displayed in the views of Fig. 6.

As can be seen in Figs. 1-3 of supplementary info, at room temperature, the failure modes of $\mathrm{NC}, \mathrm{SC}$ and $45 \mathrm{C}$ samples after SR and T6 are dominated by a mix of brittleductile fractures. The $Z$-struts failed in buckling mode firstly, then BCC struts dominate fracture mechanisms through a $45^{\circ}$ collapse after reaching the maximum load bearable (red lines in Figs. 1-3 of the supplementary info). These phenomena were discussed also by Ferro et al. [23]. They found that the effect of cell struts in fracture modes 


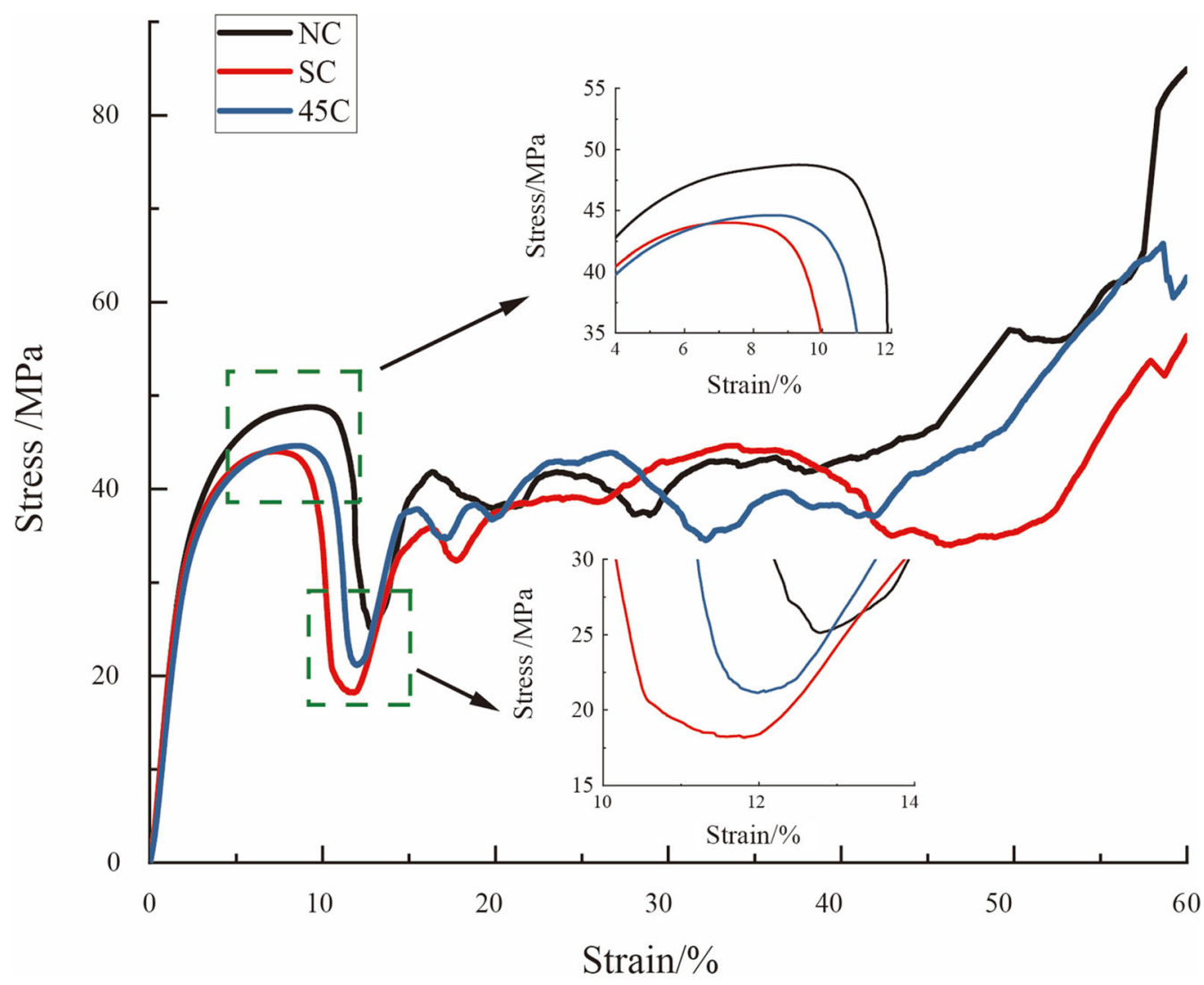

Fig. 5 Compressive stress-strain behavior obtained as mean curve for NC, SC and 45C samples after SR tested at $25^{\circ} \mathrm{C}$

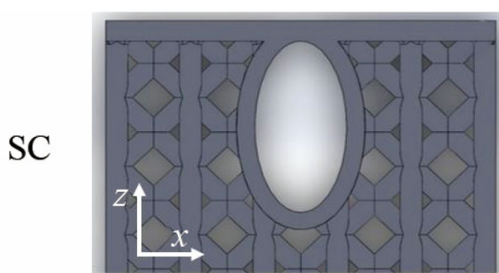

(a)

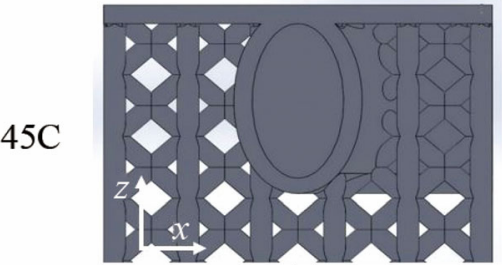

(c)

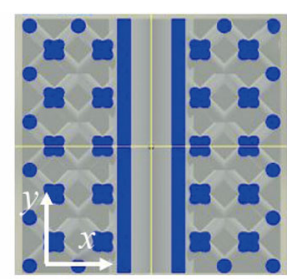

(b)

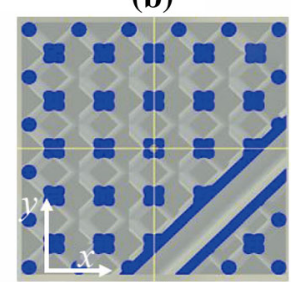

(d)
Fig. 6 CAD drawings of SC a, b and $45 \mathrm{C} \mathbf{c}, \mathbf{d}$ samples with frontal view $\mathbf{a}-\mathbf{c}$ and top section of the channel mid-plane $\mathbf{b}, \mathbf{d}$, respectively

was negligible if cells were localized in other planes distant from the one of the rupture. Only at the end of the compression test, they all tend to collapse.

Considering the compression test at $200{ }^{\circ} \mathrm{C}$, there is not an appreciable variation in the quasi-elastic gradient between different types of samples, as reported in Table 5.
Table 5 Static compressive properties of NC, SC and 45C samples after SR and T6 tested at $200{ }^{\circ} \mathrm{C}$

\begin{tabular}{llllll}
\hline & \multicolumn{2}{l}{ Quasi-elastic gradient $/ \mathrm{GPa}$} & & \multicolumn{2}{l}{ Yield strength $/ \mathrm{MPa}$} \\
\cline { 2 - 3 } \cline { 6 - 7 } & SR & T6 & & SR & T6 \\
\hline NC & $1.8 \pm 0.2$ & $1.8 \pm 0.0$ & & $23.4 \pm 3.6$ & $19.2 \pm 0.4$ \\
SC & $1.6 \pm 0.2$ & $1.9 \pm 0.1$ & & $22.2 \pm 1.1$ & $23.0 \pm 3.3$ \\
$45 C$ & $1.8 \pm 0.2$ & $1.7 \pm 0.1$ & & $21.6 \pm 1.1$ & $20.4 \pm 1.3$ \\
\hline
\end{tabular}

While it is possible to note a net decrease in yield strength up to $30 \%$ less respect to room temperature values.

This occurs consistently for NC, SC and 45C treated with both SR and T6. The curves recorded for all types of the AlSi10Mg BCCZ samples present constant trends, as illustrated in Fig. 7. At this temperature, samples behave as metal foams. As observable in Fig. 7, the stress-strain graphs can be divided into 3 sections: in the first part there is a perfectly elastic behavior. Then a plateau zone follows, up to $40 \%$ of the deformation, and finally stresses increase as a consequence of the sample densification. The possibility of densifying and achieving a foam-like behavior can be ascribed to the increase in temperature. 


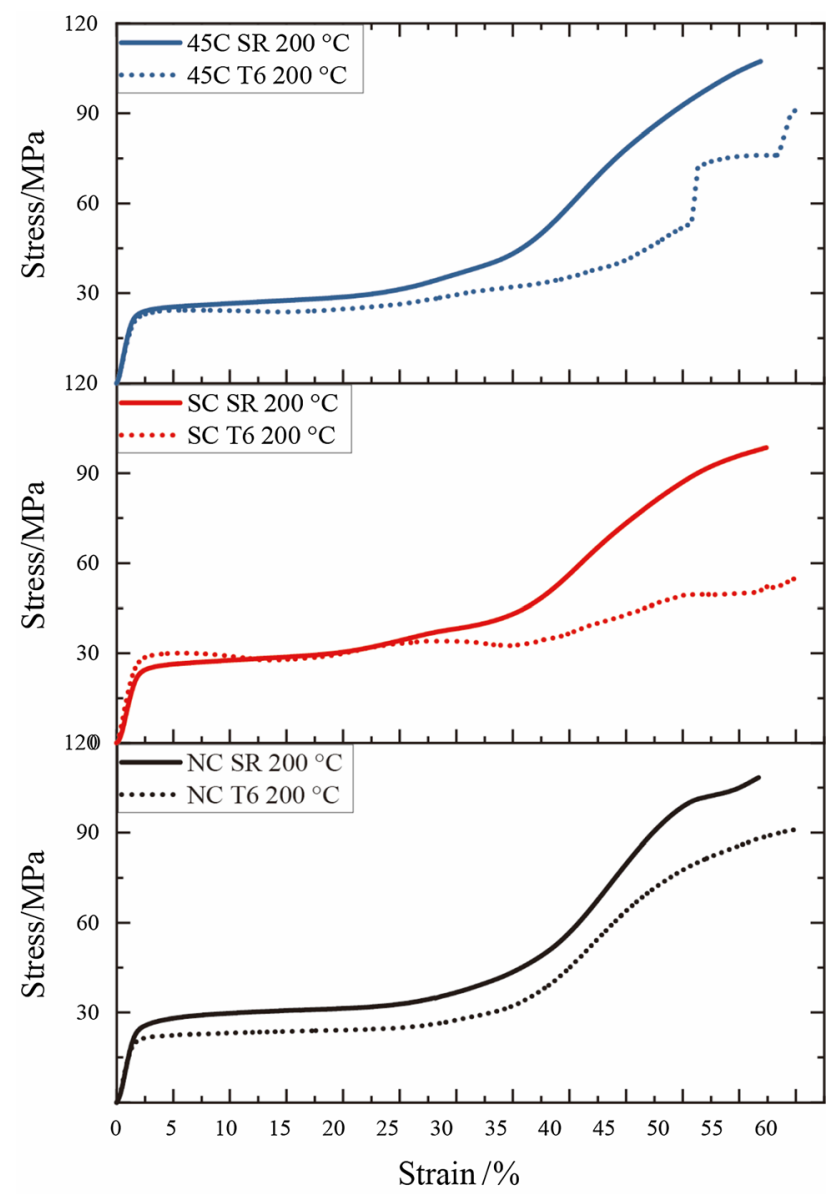

It is known that at $200{ }^{\circ} \mathrm{C} \mathrm{AlSi10Mg} \mathrm{samples} \mathrm{exhibit} \mathrm{a}$ lower strength and a higher elongation at break in tensile test, making the mechanical behavior of this alloy similar to the one of a ductile pure metal at room temperature [39]. Therefore the failure mode of all configurations is dominated by a ductile fracture, reaching the same level of densification as visible in Fig. 8. The struts along $Z$ axis avoid euler buckling mode failure while BCC cells inside the sample fold in predictable way thanks to the high elongation at rupture. This kind of plastic collapse could be described by the mean curves of Fig. 7, similarly to aluminum metal open-cell foams [40].

At $200{ }^{\circ} \mathrm{C}$, SR samples have a metal-foam like deformation in each type of lattice (NC, SC or $45 \mathrm{C}$ ); moreover the curves are extremely repeatable in every configuration. T6 samples have a plateau stress lower or equal to those of the SR specimens with non-constant deformations, as illustrated in Fig. 7. This can be attributed also to a lower level of densification at the end of the test of the lattice samples in T6 condition with respect to SR.

Considering that $\mathrm{T} 6$ treatment needs higher furnace temperatures and longer process times, being more expensive and time-consuming than the SR one, the SR condition results in the best choice for possible applications of aluminum lattice structures with conformal coils as part of lightweight heat exchangers.

Fig. 7 Compressive stress-strain behavior obtained as mean curve for $\mathrm{NC}, \mathrm{SC}$ and $45 \mathrm{C}$ samples after SR and T6 tested at $200{ }^{\circ} \mathrm{C}$

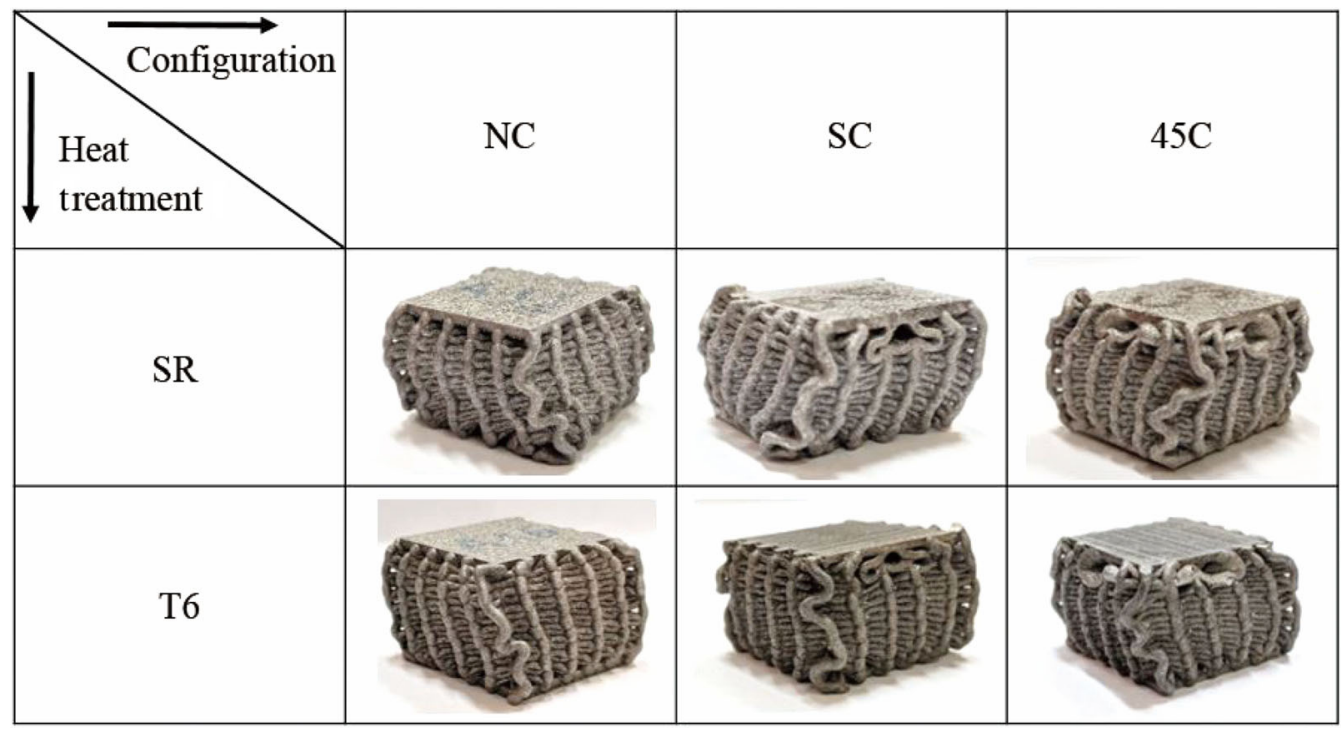

Fig. 8 Evaluation of densification level for each configuration and condition tested at $200{ }^{\circ} \mathrm{C}$ 


\section{Conclusions}

In this study three different configurations of AlSi10Mg lattice structures by LPBF were tested in compression at 25 ${ }^{\circ} \mathrm{C}$ and $200{ }^{\circ} \mathrm{C}$. The reference structures were BCCZ lattices, BCC in the core of the samples with vertical struts along $Z$ in the outer perimeter [23], labelled as NC samples. The main novelty consisted in inserting a straight elliptical channel and a $45^{\circ}$ elliptical channel inside the BCCZ lattice structures, labelled as SC and $45 \mathrm{C}$ samples, respectively. In fact, the use of cooling channels inside lattice structures is of great potential interest for many industrial sectors, such as mold industry, aerospace and automotive. Therefore, all the samples were tested after LPBF process, in $\mathrm{AB}$ condition, and after two post process heat treatments, commonly used for AlSi10Mg LPBF industrial components: an SR and a T6 treatment.

The main findings observed regarding the fracture behavior under compressive tests of these above mentioned samples are summarized as follows.

(i) $\mathrm{NC}$ lattice structures $\mathrm{AB}$ exhibited an overall fragile fracture; they were considered as a condition not useful for the fabrication of complex parts, and therefore the $\mathrm{SC}$ and $45 \mathrm{C}$ configuration samples were tested only after thermal treatments.

(ii) The test at room temperature showed that all types of samples were characterized by negligible variations in their quasi-elastic gradients and yield strength ensuring similar structural responses by configurations with or without channel.

(iii) On the contrary, the general trend of stress-strain curves is influenced by the presence of the channel and its position. The slightly greater resistance of the $45 \mathrm{C}$ samples compared to the SC samples can be attributed to the number of elementary cells substituted by the presence of the channel: 10 cells for SC and 7 cells for $45 \mathrm{C}$.

(iv) The test at $200{ }^{\circ} \mathrm{C}$ showed that $\mathrm{NC}, \mathrm{SC}$ and $45 \mathrm{C}$ samples after SR and T6 treatments exhibited a metal-foam like deformation. SR samples can sustain a higher stress than T6 specimens. This can be attributed to a higher level of densification with a constant deformation at the end of the test of the lattice samples in SR condition with respect to T6.

(v) Considering that T6 treatment needs higher furnace temperatures and longer process times, being more expensive and time-consuming than the SR one, the SR condition results in the best choice for possible applications of aluminum lattice structures with conformal coils as part of lightweight heat exchangers.
Funding Open access funding provided by Politecnico di Torino within the CRUI-CARE Agreement.

Open Access This article is licensed under a Creative Commons Attribution 4.0 International License, which permits use, sharing, adaptation, distribution and reproduction in any medium or format, as long as you give appropriate credit to the original author(s) and the source, provide a link to the Creative Commons licence, and indicate if changes were made. The images or other third party material in this article are included in the article's Creative Commons licence, unless indicated otherwise in a credit line to the material. If material is not included in the article's Creative Commons licence and your intended use is not permitted by statutory regulation or exceeds the permitted use, you will need to obtain permission directly from the copyright holder. To view a copy of this licence, visit http://creativecommons. org/licenses/by/4.0/.

\section{References}

1. Eiamsa-Ard K, Wannissorn K (2015) Conformal bubbler cooling for molds by metal deposition process. CAD Comput Aided Des 69:126-133

2. Soshi M, Ring J, Young C et al (2017) Innovative grid molding and cooling using an additive and subtractive hybrid CNC machine tool. CIRP Ann - Manuf Technol 66:401-404

3. Gibson LJ, Ashby MF (1988) Cellular Solids: Structure \& Properties. Pergamon Press, UK

4. Cheng L, Liu J, Liang X et al (2018) Coupling lattice structure topology optimization with design-dependent feature evolution for additive manufactured heat conduction design. Comput Methods Appl Mech Eng 332:408-439

5. Wu T, Jahan SA, Zhang Y et al (2017) Design Optimization of Plastic Injection Tooling for Additive Manufacturing. Procedia Manuf 10:923-934

6. Yun S, Kwon J, Lee DC et al (2020) Heat transfer and stress characteristics of additive manufactured FCCZ lattice channel using thermal fluid-structure interaction model. Int J Heat Mass Transf 149:119187

7. Mahshid R, Hansen HN, Højbjerre KL (2016) Strength analysis and modeling of cellular lattice structures manufactured using selective laser melting for tooling applications. Mater Des 104:276-283

8. Brooks H, Brigden K (2016) Design of conformal cooling layers with self-supporting lattices for additively manufactured tooling. Addit Manuf 11:16-22

9. Mazumder J, Choi J, Nagarathnam K et al (1997) The direct metal deposition of $\mathrm{H} 13$ tool steel for 3-D components. JOM 49:55-60

10. Leary M, Mazur M, Williams $H$ et al (2018) Inconel 625 lattice structures manufactured by selective laser melting (SLM): Mechanical properties, deformation and failure modes. Mater Des 157:179-199

11. Köhnen P, Haase C, Bültmann J et al (2018) Mechanical properties and deformation behavior of additively manufactured lattice structures of stainless steel. Mater Des 145:205-217

12. Yan C, Hao L, Hussein A et al (2012) Evaluations of cellular lattice structures manufactured using selective laser melting. Int J Mach Tools Manuf 62:32-38

13. Yan C, Hao L, Hussein A et al (2014) Advanced lightweight $316 \mathrm{~L}$ stainless steel cellular lattice structures fabricated via selective laser melting. Mater Des 55:533-541

14. Choy SY, Sun CN, Leong KF et al (2017) Compressive properties of functionally graded lattice structures manufactured by selective laser melting. Mater Des 131:112-120 
15. Leary M, Mazur M, Elambasseril J et al (2016) Selective laser melting (SLM) of AlSi12Mg lattice structures. Mater Des 98:344-357

16. Ozdemir Z, Hernandez-Nava E, Tyas A et al (2016) Energy absorption in lattice structures in dynamics: Experiments. Int $\mathbf{J}$ Impact Eng 89:49-61

17. Harris JA, Winter RE, McShane GJ (2017) Impact response of additively manufactured metallic hybrid lattice materials. Int $\mathbf{J}$ Impact Eng 104:177-191

18. Chen L, Zhang J, Du B et al (2018) Dynamic crushing behavior and energy absorption of graded lattice cylindrical structure under axial impact load. Thin-Walled Struct 127:333-343

19. Li C, Lei H, Liu Y et al (2018) Crushing behavior of multi-layer metal lattice panel fabricated by selective laser melting. Int $\mathbf{J}$ Mech Sci 145:389-399

20. Yan C, Hao L, Hussein A et al (2015) Microstructure and mechanical properties of aluminium alloy cellular lattice structures manufactured by direct metal laser sintering. Mater Sci Eng A 628:238-246

21. Qiu C, Yue S, Adkins NJE et al (2015) Influence of processing conditions on strut structure and compressive properties of cellular lattice structures fabricated by selective laser melting. Mater Sci Eng A 628:188-197

22. Yan C, Hao L, Hussein A et al (2014) Evaluation of light-weight AlSi $10 \mathrm{Mg}$ periodic cellular lattice structures fabricated via direct metal laser sintering. J Mater Process Technol 214:856-864

23. Ferro CG, Varetti S, Maggiore P et al (2018) Design and characterization of trabecular structures for an anti-icing sandwich panel produced by additive manufacturing. J Sandw Struct Mater 22:1111-1131

24. Maskery I, Aboulkhair NT, Aremu AO et al (2016) A mechanical property evaluation of graded density Al-Si10-Mg lattice structures manufactured by selective laser melting. Mater Sci Eng A 670:264-274

25. Maskery I, Aboulkhair NT, Aremu AO et al (2017) Compressive failure modes and energy absorption in additively manufactured double gyroid lattices. Addit Manuf 16:24-29

26. Salmi A, Atzeni E (2017) History of residual stresses during the production phases of AlSi10Mg parts processed by powder bed additive manufacturing technology. Virtual Phys Prototyp $12: 153-160$

27. Aboulkhair NT, Maskery I, Tuck C et al (2016) The microstructure and mechanical properties of selectively laser melted AlSi10Mg: The effect of a conventional T6-like heat treatment. Mater Sci Eng A 667:139-146

28. Li W, Li S, Liu J et al (2016) Effect of heat treatment on AlSilOMg alloy fabricated by selective laser melting: Microstructure evolution, mechanical properties and fracture mechanism. Mater Sci Eng A 663:116-125

29. Takata N, Kodaira H, Sekizawa K et al (2017) Change in microstructure of selectively laser melted AlSi10Mg alloy with heat treatments. Mater Sci Eng A 704:218-228

30. Eos O, Speed PA, Eos O et al (2014) Material data sheet EOS aluminium AlSi10Mg material data sheet technical data. Available via EOS. http://www.eos.info/de. Accessed 23 Sept 2020

31. Hathaway BJ, Garde K, Mantell SC et al (2018) Design and characterization of an additive manufactured hydraulic oil cooler. Int J Heat Mass Transf 117:188-200

32. Manfredi D, Calignano F, Krishnan M et al (2013) From powders to dense metal parts: Characterization of a commercial alsimg alloy processed through direct metal laser sintering. Materials 6:856-869
33. Diego M, Flaviana C, Manickavasagam K et al (2016) Additive manufacturing of $\mathrm{Al}$ alloys and aluminium matrix composites (AMCs). Intech 1:13

34. Marola S, Manfredi D, Fiore G et al (2018) A comparison of selective laser melting with bulk rapid solidification of AlSi10Mg alloy. J Alloys Compd 742:271-279

35. Trevisan F, Calignano F, Lorusso $\mathrm{M}$ et al (2017) On the selective laser melting (SLM) of the AlSi10Mg alloy: process, microstructure, and mechanical properties. Materials 10:76

36. Standard I (2011) ISO 13314 Mechanical testing of metals, ductility testing, compression test for porous and cellular metals. Ref number ISO 13314:1-7

37. Curà F, Gallinatti AE, Sesana R (2012) Dissipative aspects in thermographic methods. Fatigue Fract Eng Mater Struct 35:1133-1147

38. Ashby M (2011) Materials selection in mechanical design, 4ed, Butterworth-Heinemann, Cambridge

39. Cao Y, Lin X, Wang QZ et al (2021) Microstructure evolution and mechanical properties at high temperature of selective laser melted AlSi10Mg. J Mater Sci Technol 62:162-172

40. Jiang B, Wang Z, Zhao N (2007) Effect of pore size and relative density on the mechanical properties of open cell aluminum foams. Scr Mater 56:169-172

41. Poonaya S, Thinvongpituk C (2007) Comparison of Energy Absorption of Various Section Steel Tubes under Axial Compression and Bending Loading. Mech Eng 590-593

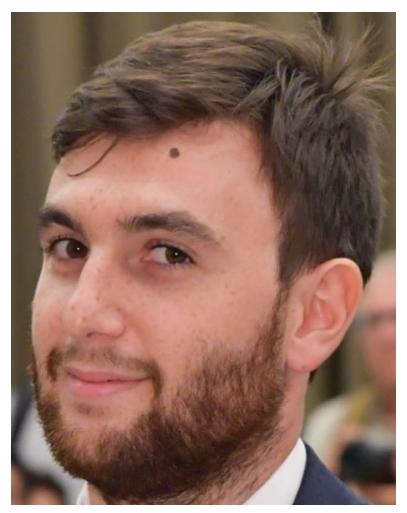

E. Virgillito is Ph.D. Candidate at Polytechnic University of Turin. He worked on mechanical characterization of Polymer Matrix Composites, powders analyses and structural simulation. His current research is focused on the production, characterization and development of innovative composition of aluminum alloys for powder based additive manufacturing technologies.

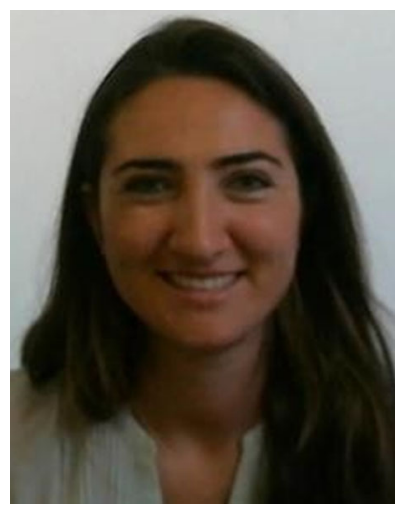

A. Aversa is Assistant Professor at Polytechnic University of Turin. Her main research interests are materials development for Additive Manufacturing processes and she focuses in particular on the characterization and the development of new Al alloys for AM processes. She participated to several Regional and European research projects focused on Additive Manufacturing processes. 


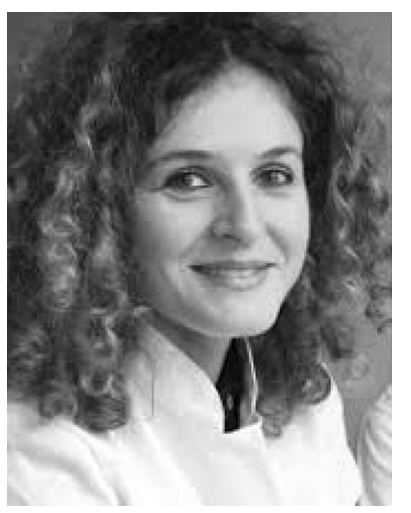

F. Calignano is Assistant Professor at Polytechnic University of Turin. Her research is focused on the study and the definition of design rules and on the final surface optimization of the parts produced through different additive manufacturing techniques. She participated to several Regional and European research projects focused on Additive Manufacturing processes.

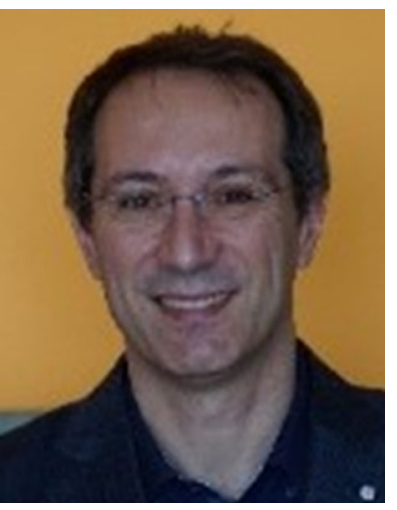

D. Ugues is Associate Professor at Polytechnic University of Turin. His research interests include microstructural features and mechanical properties provided to metallic components by the synergic effects of chemical composition, forming actions and thermal loads according to the specific manufacturing route. He participated to several Regional and European research projects focused on Additive Manufacturing processes and Hot Isostatic Pressing.

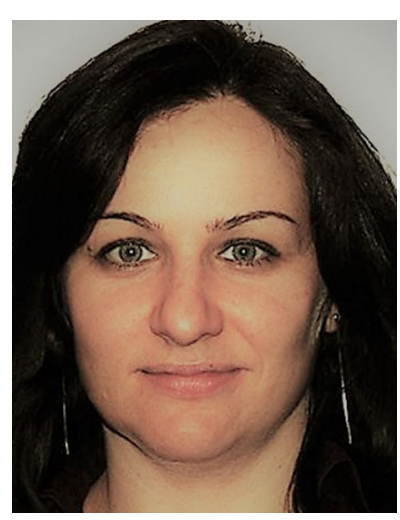

M. Lombardi is Full Professor at Polytechnic University of Turin. Her scientific activity concerned materials science and technology aspects related to the preparation and characterization of dense and porous ceramics, dense and porous polymer matrix composites, and additive manufactured metallic alloys. She participated to several Regional and European research projects focused on Additive Manufacturing processes.

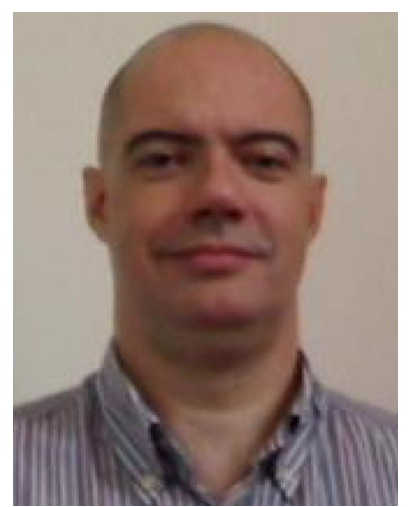

P. Fino is Full Professor at Polytechnic University of Turin. His research interests include development and characterization of ceramic powders and massive materials, metal-ceramic matrix composites, ceramic matrix composites and multi-layers, and structural materials produced through additive manufacturing technologies.

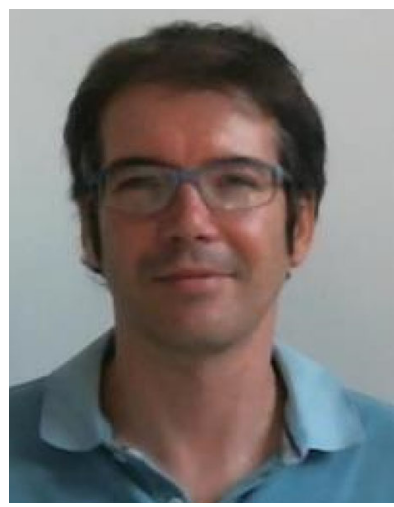

D. Manfredi is Assistant Professor at Polytechnic University of Turin. His research is focused on the development of metallic alloys through the additive manufacturing technology and their complete microstructural characterization. $\mathrm{He}$ participated to several Regional and European research projects focused on Additive Manufacturing processes. 